\title{
Fourier Transform Infrared (FTIR) Spectroscopy of Soil Humic and Fulvic Acids Extracted from Paddy Land Use System
}

\author{
Sharan Bhoopal Reddy ${ }^{1 *}$, M.S. Nagaraja ${ }^{2}$, G.G. Kadalli ${ }^{3}$ and B.V. Champa ${ }^{2}$ \\ ${ }^{1}$ Agriculture College, Bheemarayanagudi-585287 (UAS, Raichur), Karnataka, India \\ ${ }^{2}$ College of Horticulture, Bagalkot - 587104 (UHS, Bagalkot), Karnataka, India \\ ${ }^{3}$ College of Agriculture, Hassan-573225 (UAS, Bengaluru), Karnataka, India
}

*Corresponding author

\section{A B S T R A C T}

\begin{tabular}{|l|}
\hline K e y w o r d s \\
$\begin{array}{l}\text { Fourier Transform } \\
\text { Infrared (FTIR) } \\
\text { Spectroscopy and Land } \\
\text { Use Systems (LUS) }\end{array}$ \\
\hline Article Info \\
\hline $\begin{array}{l}\text { Accepted: } \\
\text { 10 April 2018 } \\
\text { Available Online: } \\
\text { 10 May 2018 }\end{array}$ \\
\hline
\end{tabular}

\section{Introduction}

Humic substances are major fractions of soil organic matter and In any ecosystem status and composition of humic substances were governed by most of the factors as importantly management $>$ climate $>$ biota $>$ topography $=$ parent material > time (Garcia-Herrera et al., 2010., Lobell et al., 2011., Reddy, 2012., Reddy, 2014).

Therefore any significant influence of any of these factors will determine the content and composition of the humic substances in any particular soil. Thus, better understanding of characteristics and functional groups of humic substances induced by land use management may serve as essential guide in the study of soil organic matter en bloc. Paddy is one of the major production systems in Hassan district. Fertiliser use and frequent cultural operations in rice may greatly influence the composition of humic substances.

FTIR spectroscopy of humic substances extracted from these paddy land use systems could serve as an effective technique to know the composition of humic fractions.

Therefore, a study was carried out to know the spectral characteristics of HA and FA of paddy land use system. 


\section{Materials and Methods}

Study area (Hassan district) situated eastern side of the Western Ghats, in the southern part of Karnataka state. Fifteen surface composite soil samples $(0-0.15 \mathrm{~m})$ were pooled from 3 soil sampling points, within a pre-identified representative site from the LUS. Extraction, fractionation and purification of humic substances (HA and FA) was done following the procedures given by Stevenson (1994) and Wander and Traina (1996). Purified samples of HA and FA were subjected to FTIR spectral analysis to understand the major components and functional groups present in each fraction.

Samples were prepared in the form of pellets by mixing humic materials separately with dry $\mathrm{KBr}$ powder and pressed under vacuum at a pressure of $50-100 \mathrm{~kg} \mathrm{~cm}^{-2}$ for $20 \mathrm{~min}$ (Niemeyer et al., 1992). These pellets were fed to Shimadzu FTIR spectroscopy for spectral analysis and peaks obtained were in the range of $500-4000 \mathrm{~cm}^{-1}$.

\section{Results and Discussion}

Spectra of Fourier Transform Infrared (FTIR) spectroscopy endow with valuable information on the functional groups present in the HA and FA fractions. The spectra obtained for HA and FA fractions did not vary much with respect to the peaks obtained for same land use system at different sites, therefore spectra of paddy system of only one location is presented in Figure 1. The main absorption bands irrespective of both HA and FA were assigned as per the reference outlined by Flaig et al., (1975). The absorption spectra of HA and FA samples extracted from different soils indicate similar structure, differing only in their intensities of absorption (Stevenson, 1994).

Fig.1 FTIR spectra of (a) HA and (b) FA fractions from soils of paddy land use system

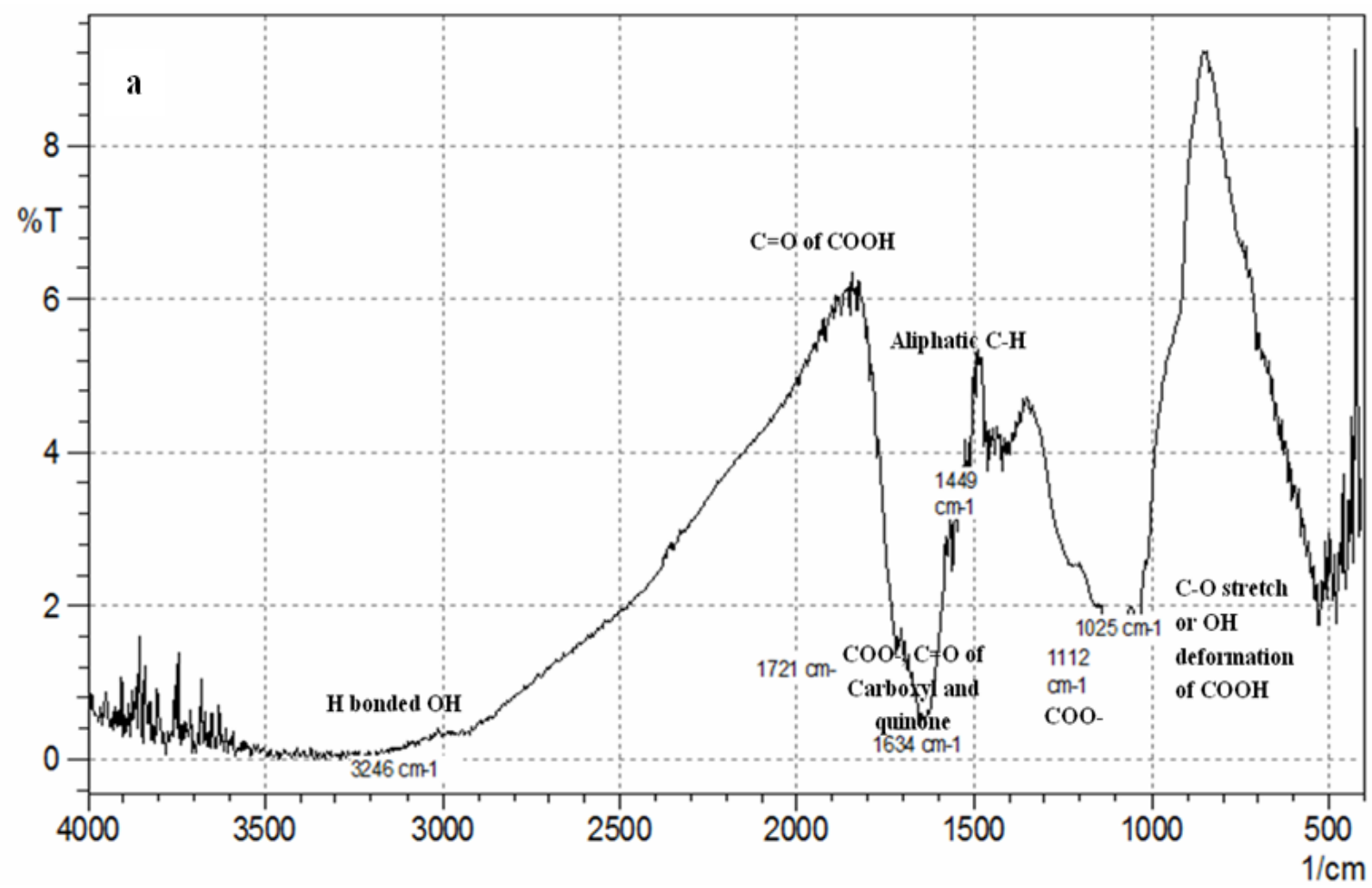




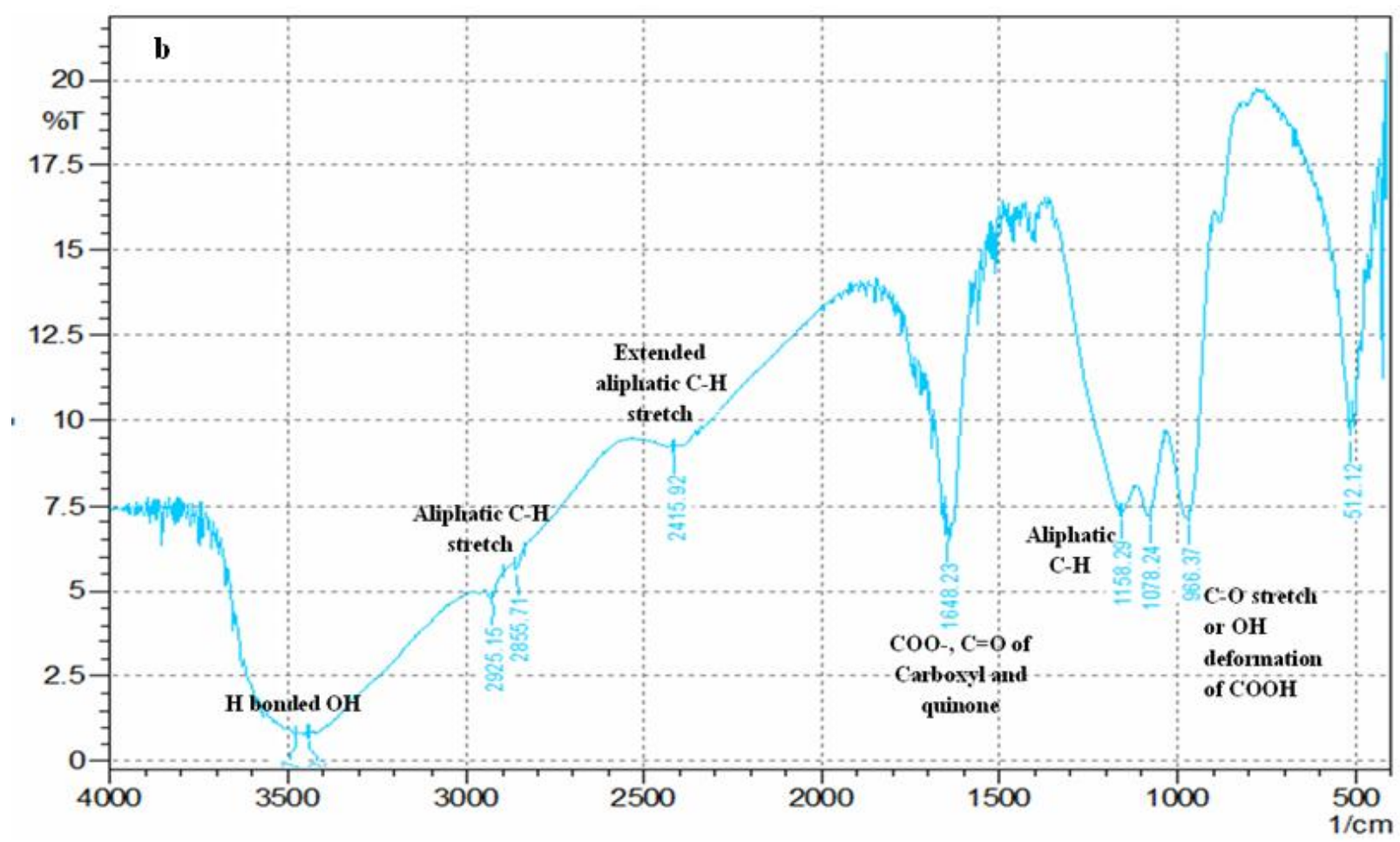

FTIR spectrum of HA of paddy soils showed bands at $3246 \mathrm{~cm}^{-1}$ (H-bonded $\left.\mathrm{OH}\right), 2420$ $\mathrm{cm}^{-1}$ (aliphatic $\mathrm{C}-\mathrm{H}$ strech), $1721 \mathrm{~cm}^{-1}(\mathrm{C}=\mathrm{O}$ of $\mathrm{COOH}, \mathrm{C}=\mathrm{O}$ stretch of ketonic $\mathrm{C}=\mathrm{O}), 1634$ $\mathrm{cm}^{-1}$ (COO-, $\mathrm{C}=\mathrm{O}$ of carbonyl and quinone), $1449 \mathrm{~cm}^{-1}$ (aliphatic C-H), $1112 \mathrm{~cm}^{-1}$ (COO-) and $1102 \mathrm{~cm}^{-1}$ (C-O stretch or $\mathrm{OH}$ deformation of $\mathrm{COOH}$ ). In case of FA, the FTIR spectrum showed peaks at $3497 \mathrm{~cm}^{-1}$ (H-bonded $\mathrm{OH}$ ), $2925-2855 \mathrm{~cm}^{-1}$ (aliphatic $\mathrm{C}-\mathrm{H}$ strech), $2415 \mathrm{~cm}^{-1}$ (extended aliphatic C$\mathrm{H}$ stretch), $1648 \mathrm{~cm}^{-1}$ (COO-, $\mathrm{C}=\mathrm{O}$ of carbonyl and quinone), $1158 \mathrm{~cm}^{-1}$ (aliphatic $\mathrm{C}-\mathrm{H}$ ), $1078 \mathrm{~cm}^{-1}$ (COO-) $966 \mathrm{~cm}^{-1}$ (C-O stretch or $\mathrm{OH}$ deformation of $\mathrm{COOH}$ ) and 512 $\mathrm{cm}^{-1}$. All the spectra showed a strong absorption band at $3450-3345 \mathrm{~cm}^{-1}$, indicating extensive overlapping of the $\mathrm{OH}$ groups with various degree of $\mathrm{H}$-bonding. A weak band at $1725 \mathrm{~cm}^{-1}$ in HAs and medium in FAs indicate higher number of $\mathrm{COOH}$ groups in the latter. The band of medium to strong intensity at $1300 \mathrm{~cm}^{-1}$ indicate that HAs and FAs may be present in the form of the salts of $\mathrm{COOH}$, whereas, the strong and broad band near $1200 \mathrm{~cm}^{-1}$ suggest C-O stretching of aromatic ethers in all HAs and FAs (Schnitzer, 2000).

Present study revealed that FTIR characterization resulted in better understanding of humic substances composition, functional groups in respective humic material as influenced by paddy land use practices. This work supports further for the studies involving land use systems influence on characteristics of humic substances.

\section{References}

Flaig, W., Benielspacher, H. and Reitz, E. 1975. Soil Components. SpringerVerlag, New York, pp 1-211.

Garcia-Herrera, R., Diaz, J., Trigo, R.M., Luterbacher, J. and Fischer, E. M. 2010. A review of the European summer heat wave of 2003. Crit. Rev. Environ. Sci. 
Technol. 40:267-306. doi: 10.1080/106 43380802238137.

Lobell, D.B., Schlenker W, Costa-Roberts J (2011) Climate trends and global crop production since 1980. Science. 333:616-620.

Niemeyer, J., Chen, Y. and Bollag, J. M. 1992. Charactrization of humic acids, composts, and peat by diffuse reflectance Fourier transform Infrared Spectroscopy. Soil Sci. Soc. Amer. J. 56: 135-140.

Reddy, S.B., Nagaraja, M.S., Punith Raj, T.S., Police Patil, A.S. and Prabhudev Dhumgond. 2014. Elemental analysis, E4/E6 ratio and total acidity of soil humic and fulvic acids from different land use systems. Annals Plant Soil Res. 16(2): 89-92.
Reddy, S.B., Nagaraja, M.S., Punith Raj, T.S., Prabhudev Dhumgond and Vignesh, N.S. 2012. Soil humic and fulvic acid fractions under different land use systems. Madras Agril. J. 99 (7-9): 507510.

Schnitzer, M. 2000. Lifetime perspective on the chemistry of soil organic matter. Adv. in Agronomy, 68: 1-58.

Stevenson, F. J. 1994. Humus Chemistry: Genesis, Composition and Reactions. John Wiley and Sons Publications, New York, pp 1-512.

Wander, M. M. and Traina, S. J. 1996. Organic matter fractions from organically and conventionally managed soils: II. Characterization of composition. Soil Sci. Soc. Am. J., 60: 1087-1094.

\section{How to cite this article:}

Sharan Bhoopal Reddy, M.S. Nagaraja, G.G. Kadalli and Champa, B.V. 2018. Fourier Transform Infrared (FTIR) Spectroscopy of Soil Humic and Fulvic Acids Extracted from Paddy Land Use System. Int.J.Curr.Microbiol.App.Sci. 7(05): 834-837. doi: https://doi.org/10.20546/ijcmas.2018.705.102 